\title{
¿Cómo hacer cultura? La vía romana o la sublimación cultural como proceso civilizador
}

\author{
ASHER GUTKIND*
}

Artículo recibido: 6 de diciembre de 2013

Artículo aprobado: 10 de abril de 2014

Doi: dx.doi.org/10.12804/desafios26.1.2014.03

Para citar este artículo: Gutkind, A. (2014). ¿Cómo hacer cultura? La vía romana o la sublimación cultural como proceso civilizador. Desafíos, 26 (1), 83-120. doi: dx.doi.org/10.12804/ desafios26.1.2014.03

\section{Resumen}

Quisiéramos proponer una reflexión sobre los debates contemporáneos que tratan del lugar de la cultura y de la educación a partir de la tesis de la vía romana, entendida como aculturación positiva y cultura excéntrica, propuesta por Brague. Se trata de una discusión filosófica y de una revisión conceptual acerca del lugar de la cultura en el devenir humano. Se discuten las concepciones de Bourdieu, Freudy Brague, para proponer un concepto que deseamos sea una agrupación en aras de una idea de la cultura: la sublimación cultural. Este concepto está pensado para contribuir al debate sobre la teoría de la cultura, en especial la cuestión de la cultura general frente a las culturas particulares, a fin de pensar la universalidad problemática de la idea de cultura. Nuestra propuesta se basa en la idea de que la bistoria europea se ha caracterizado por apropiarse e inventar su idea de cultura como la forma ideal de ser.

Palabras clave: teoría de la cultura occidental, vía romana, sublimación * Maîtrise, profesor de cátedra de la Escuela de Ciencias Humanas, Universidad del Rosario.
Correo electrónico: ash.gut@gmail.com 


\title{
How to Make Culture? The Roman Path or Cultural Sublimation as a Process of Civilization
}

\begin{abstract}
In this article I propose a reflection on contemporary debates dealing with the place of culture and education. I start with the Roman path thesis, understood as positive acculturation and eccentric culture, which has been proposed by Brague. It deals with a philosophical discussion and, more generally, a conceptual reflection on the place of culture within human development. I then discuss the conceptions of Bourdieu, Freud and Brague, which leads me to suggest a concept for an idea of culture: cultural sublimation. This concept is meant to contribute to the debate on the theory of culture, especially the question of general culture vs. single cultures, in order to analyze the problematic universality of the idea of culture, which European history defined as its ideal form.
\end{abstract}

Key words: Theory of Western Civilization; Roman Path; Sublimation

\section{Como fazer cultura? A via romana ou a sublimação cultural como processo civilizador}

\begin{abstract}
Resumo
Quiséramos propor neste texto uma reflexão sobre os debates contemporâneos que tratam do lugar da cultura e da educação, a partir da tese da via romana entendida como aculturação positiva e cultura excêntrica, proposta por Brague. Trata-se de uma discussão filosófica e, em geral, de uma reflexão conceitual sobre o lugar da cultura no devir humano. Discute-se das concepcões de Bourdieu, Freud e Brague, para propor um conceito que quiséramos que fosse uma agrupação em favor de uma ideia da cultura: a sublimação cultural. Este conceito está pensado para contribuir ao debato sobre a teoria da cultura, especialmente a questão da cultura geral versus as culturas particulares, a fim de tratar de pensar a universalidade problemática da ideia de cultura, da qual a bistória europeia propôs-se fazer sua forma ideal.
\end{abstract}

Palavras- chave: Teoria da Cultura Ocidental; via romana; skhole; sublimação; pulsões 
Denomino existir, extraerse. Para ello, hay que entrar en el viaje...

"There are considerable men", he said. "I know. But have you listened to their conversation? They don't seem to have understood anything that they have seen bere". Conrad (2007).

Europa debe, al contrario, proponerse a si misma como ella lo propone al resto del mundo, la europeización como tarea. Brague (2009a).

\section{Naturaleza y lugar de la cultura en el debate intelectual y político: presentación}

En el debate contemporáneo, hemos observado el desarrollo de la idea según la cual la educación está basada en la "dominación de una cultura legítima". De acuerdo con la "sociología crítica de la dominación" de Bourdieu (1982; 2003), un "poder simbólico" sentaría las bases de una dominación de una cultura legítima particular proveniente de las élites dominantes en el espacio social.

Estas ideas de Bourdieu fueron retomadas por nuevas corrientes de pensamiento que se apropiaron de ellas para analizar, alrededor de los conceptos de "eurocentrismo" y de "hegemonía cultural hemisférica", una crítica de la cultura europea en sí misma y como una totalidad. Ahora bien, proponemos debatir sobre las tesis que afirman que existe una "hegemonía cultural" que domina la educación general.

En resumidas cuentas, nuestra posición se basa en la afirmación sobre una cultura europea que estructura las condiciones de posibilidades sociohistóricas que, en una historia y una sociología singulares, hacen emerger el estudio científico en sí mismo, la búsqueda de lo universal por sí mismo. Para fundamentar esta investigación se requieren condiciones históricas y sociales particulares: la skhole, según el concepto que Bourdieu desarrolla en Méditations Pascaliennes (2003), plantea un habitus particular para el estudio universitario, un ethos necesario expresado en el espacio social de la skhole que forma un capital cultural, lo que instaura un espacio para que un valor y un interés por la verdad puedan ejercerse en el campo científico y en la skhole. 
Nuestra proposición consiste en afirmar que la skbole pensada por Bourdieu se basa en un "método de hacer cultura" (Brague, 2009a p. 168). En efecto, toda cultura posee una voluntad de poder, un deseo en sí, hegemónico: de la misma manera que un niño puede pensarse todopoderoso y centro del universo, una cultura se piensa como un imperio universal, la elegida del Sol o de la transcendencia. Una cultura así entendida se cree indiscutible, omnisciente y superior a las demás, al menos en sus presupuestos originarios, filosóficos y religiosos, sin posibilidad de un examen crítico de su "visión de mundo".

De este esquema se ha separado un proyecto y una idea cultural europea que plantean las bases para crear una "cultura excéntrica". Los fundamentos referenciales de esta cultura se sitúan fuera de ella misma y se propone pensarse como "mi cultura como otra" a partir de un "complejo positivo de inferioridad", de la "secundariedad cultural y religiosa" y de una idea positiva de la "aculturación" con lo que se impone a sí misma un camino abierto e indeterminado hacia un "método de hacer cultura".

De esta manera, se diferencia mi origen cultural y el proceso de hacer cultura: esto es la vía romana, para la que no hay origen cultural. Es solo un acto humano para hacerla existir por un tiempo, luego hacerla existir de nuevo y así sucesivamente. Esto hizo posible la formación de modos de apropiación cultural no caníbal sino de inclusión, que rechaza la centralidad y el esencialismo y hacen lugar en sí mismos para la recepción y la investigación aún no concluida, en tensión y en apertura, de lo universal. Podríamos resumirla en una fórmula anglófona utilizada en la traducción norteamericana de la voie romaine: "Eccentric Culture" (Brague, 2009b).

Nuestra proposición conceptual, que llamamos la sublimación cultural, indica esa aptitud moral e intelectual del hombre que posibilita sublimar la economía pulsional, cuyas estructuras se inscriben en la cultura original que modela el inconsciente cultural de cada uno. La sublimación cultural pasa por el hecho de extraerse, al menos en su psiquis y su conciencia, de su cultura original y por un esfuerzo moral e intelectual en la investigación racional, en ella, por ella y para ella; 
esto puede hacer trabajar el inconsciente cultural producido por esta cultura original hacia una sublimación que permite libertad y verdadera conciencia ante las economías pulsionales. Esta capacidad da la posibilidad psíquica y práctica para una voluntad de lo universal.

Por ejemplo, este proceso cultural se hace visible en las ciencias de la religión, ${ }^{1}$ al reconocer lo más sagrado para el otro y para sí mismo. La conciencia de sí mismo es voluntad de universal, pero vivir por lo universal solo puede hacerse como "hombre libre de tutelas", como lo invocaba la filosofía de Kant (2006). Es muy posible que estas condiciones de conocimientos y de reconocimiento a partir del estudio científico no confesional de las religiones únicamente pueda realizarse en instituciones educativas no confesionales orientadas por los métodos científicos de comprensión de los textos y las ideas: la filología de los textos sagrados (Stroumsa, 2010). Para que esto sea posible, la presencia de entidades políticas — del Estado liberal- es necesaria para garantizar que las personas existan no solo en tanto individuos singulares que viven de lo universal, sino también como ciudadanos del Estado, recopilación de las voluntades políticas del pueblo.

Proponemos, entonces, articular tres conceptos: sublimación (Freud), skhole (Bourdieu) y vía romana (Brague), a fin de formar el concepto de sublimación cultural.

Ser hombre sería un deber-ser hombre para un hacerse-hombre en la superación de nuestra propia pulsión cultural para una aculturación razonada que nos permita tener una actitud única y universal: la vía romana, modificada, transformada y reformulada, que sigue una antropología del proceso civilizador como sublimación cultural. La aculturación se entiende aquí como positiva en la medida en que esta operación cultural facilita al individuo el alcance de una verdadera libertad en la conciencia de sí mismo, de su humanidad propia, lo que es propio de la vía romana.

\footnotetext{
1 Entre otras ramificaciones, indagaremos con mayor profundidad sobre el ejemplo de las ciencias de las religiones como una expresión privilegiada de la vía romana o de la sublimación cultural como proceso civilizador.
} 


\section{8 / Asher GUtKInd}

No hay "cultura europea" ni "Europa" ni "europeos": solo hay cultura y no pertenece a los europeos ni a los no europeos, sino a aquellos, europeos y no europeos, que producen los esfuerzos y consagran su trabajo sobre sí mismos para tender hacia y hacer lugar a lo universal. Brague (2009a) lo expresa así:

La conciencia que tenía Europa, la de tener sus fuentes fuera de sí-misma, tiene como consecuencia un desplazamiento de su identidad cultural, tal que su única identidad cultural es una identidad excéntrica [...]. Yo diría pues a los europeos: "ustedes no existen". No hay europeos. Europa es una cultura. Ahora bien, la cultura es un trabajo sobre sí mismo, un esfuerzo para asimilar lo que supera al individuo. Por consiguiente, ella no puede ser heredada. Al contrario, ella tiene que ser conquistada por cada uno. No se puede nacer europeo pero se puede trabajar para convertirse en europeo [...]. Volviéndome ahora hacia los no-europeos, les diría: “justedes tampoco existen!". El mundo entero, para su felicidad o para su desgracia, fue recorrido por europeos y sigue afectado por lo europeo, por fenómenos venidos de Europa. Y ante éstos, el resto del mundo — si se puede hablar así- está alojado en el mismo barco que lo que ya es europeo, o que se cree tal [...]. Europa debe, al contrario, proponerse a sí-misma, así como lo propone al resto del mundo, la europeización como tarea (2009a, pp. 170, 188, 190).

La cultura ya no está concebida como el origen, sino como la finalidad de y hacia donde el ser humano debe tender, sin tener jamás la posibilidad de alcanzar la realización perfecta, en el sentido pleno de lo universal; a esto podemos tender y desear con plena conciencia, en una vida posible para lo universal, tal vez, ¿una vida filosófica?

Parece que la idea de la vía romana, reformulada aquí como sublimación cultural, escapa a la "crítica de la razón escolástica" que propone Bourdieu (2003). Recordemos que, según Bourdieu, la "razón escolástica" tiene que ser historizada y sociologizada, es decir, puesta de vuelta en el sentido común y social del que ella proviene. Ahora bien, para Brague no se trata de negar el origen histórico y social de la idea 
de cultura: en efecto, según él, esta tiene una historia y una sociología muy particulares: "la vía romana". La relación cultural particular de Europa está formada de manera que ha buscado sus referentes e ideales culturales fuera de sí misma y se propone a sí misma una aculturación cultural para un camino hacia lo universal de la cultura. Es al hacer lugar en sí misma y desengrasar su carácter indígena que la idea de "hacer cultura" abre la vía (romana en su origen, pero en sí, universal) hacia la preparación a formarse para lo universal.

Este proceso, este método, esta relación que Europa se propuso a sí misma, esta forma cultural europea solo es europea como europeización. En este sentido, la cultura no tiene contenido, sino un ideal: puede funcionar bien para todo el mundo. El europeo no debe olvidar que no hay nada que se pueda considerar como adquirido cuando se trata de cultura y que la barbarie está siempre cercana; mucho más cercana de lo que se cree. Asimismo, que jamás debemos creernos ya en la cultura: tenemos que retomar siempre la vía romana, esa tensión indefinida hacia la cultura. El no europeo, por su parte, no está menos distante de la cultura, en tanto que es humano y que también ha sido contaminado por el europeo. Así, no son esos residuos o esos pedazos derivados de Europa los que le impiden tender hacia la cultura. La europeización es, en sí, el método de hacer cultura propuesto a todos los hombres: no se trata, por supuesto, de llegar a ser como europeos ni de adoptar la cultura europea, sino de aculturarse, al despojarse del dominio de una identidad cultural nativa, para dar paso a un proceso de hacer cultura en sí mismo, de la misma manera como los europeos deben proponérselo a ellos mismos.

Se trata de superar tanto la carga historicista-agonística de la sociología crítica de la dominación — que parece desear reducirlo todo al hecho social de la dominación — como la crítica del psicoanálisis de las pulsiones y de la sublimación, que consiste quizás en condenar la cultura al determinismo de las pulsiones y debe reducirse a mecanismos de defensa en donde la sublimación representa el proceso más "elevado".

Según nuestra proposición, la sublimación cultural consistiría en pensar, igual que Bourdieu, que deben existir condiciones históricas 
y sociales de posibilidad para que la vía romana pueda aparecer: hay, en efecto, condicionamientos sociohistóricos para que la búsqueda de lo universal aparezca como ideal de civilización y en pensar, igual que Freud, que es necesario superar las tensiones debidas al desarrollo de los deseos del yo egocéntrico, que se chocan con el principio de realidad.

Los maestros estoicos habían propuesto ese ideal como una manera de vivir por medio de la filosofía, que Marco Aurelio presentó sin duda mejor que muchos otros, en el siguiente aforismo:

El maestro interior, cuando se conforma a la naturaleza, considera los acontecimientos de tal manera de poder siempre, según la posibilidad que tenga, modificar sin pena su actitud hacia éstos. No tiene preferencia por ninguna materia determinada pero una vez hecha su elección, se lanza hacia lo que cree lo mejor. Y si encontrase un obstáculo, hace de éste una materia, como el fuego cuando él se convierte en amo de las cosas que se le tiran, mientras que una lamparita se ahogaría ahí. Pero un fuego ardiente se apropia rápidamente de aquello que se le tira adentro; lo consume y, gracias a lo que se le tira, se eleva más alto (1992, pp. 92-93).

Dominar sus pulsiones, según el maestro estoico, ya no constituye un medio para transformarlas en algo más útil o más elevado, sino para hacer entrar en uno mismo - que es microcosmos- en armonía con el orden de la naturaleza — que es macrocosmos—. Tal como lo proponemos, si seguimos un poco el ejemplo del maestro estoico, el concepto de sublimación cultural quiere ser una manera de "modificar su actitud ante los acontecimientos", a fin de convertirlos en una materia de la que el "maestro interior" hará el fuego que le permitirá crecer interiormente, o sea, acercarse a la naturaleza, lo que significa obedecer al mandamiento de Dios. El objetivo de la filosofía (el objetivo de la cultura) es, entonces, dejar de depender de sus propios apetitos egoístas, a fin de depender solo del orden de la naturaleza.

Tratamos de retomar el desarrollo teórico sobre la libido para invertir la proposición freudiana. Estamos condenados a las pulsiones, a los 
apetitos de nuestro cuerpo, pero ninguna determinación de los reinos de los medios y de los apetitos tiene que encerrarnos en el círculo infernal de la frustración y la sublimación de las pulsiones por medio de mecanismos de defensa. De hecho, en nuestra opinión, existe un "principio de placer" que no es necesariamente el único horizonte de nuestro ser. Pensamos que esta concepción del individuo se basa en una antropología que se queda corta. Tenemos una antropología mejor a nuestro alcance, pero esto necesitaría otra discusión.

Invertimos también la idea bourdiesiana de una producción social e histórica del interés y del valor por lo universal (skhole) y retomamos los términos para transformar su sentido: si la producción del deseo de búsqueda de lo universal está condicionada por situaciones históricas particulares, esto no le quita algo a la universalidad de lo universal "producido" ni a la universalización de ese deseo y de esa producción potencial. Se trataría de una "universalidad problemática" de la cultura occidental que Weber (Colliot-Thélène, 1990; 1989) bien parece haber concebido, pero únicamente si sabemos desatar los dos conceptos de cultura indígena occidental y de cultura en el sentido que Europa ha traído consigo el ideal de universalidad, es decir, en el sentido de que no se trataría de la cultura occidental, sino de la cultura a secas, ideal que el Occidente ha convertido en su "vía": la "vía romana" (Brague, 2009a).

Así, presentamos también la idea de que el hombre debe superarse a sí mismo, aunque no para llegar a una nueva especie experimental ni a una "súper humanidad", sino para hacerse humano. La superación de sí mismo no es una mística: no es que tengamos que entrar en relación con el "todo-otro", llegar al éxtasis universal, cosa peligrosa y reservada a iniciados. La sublimación cultural está bien cableada a tierra: anclado en su historia, su sociedad, su psiquis, el individuo debe superar — no olvidar ni eliminar — su cultura propia. La aculturación hace posible el ejercicio espiritual, el trabajo sobre sí mismo, la conciencia, el reconocimiento en la libertad y la búsqueda de lo universal, en una historia cultural específica aunque susceptible de universalización, la vía romana que aquí reformulamos como la sublimación cultural. 


\section{Freud y la sublimación: la sublimación como más allá del principio pulsional}

Quizá la mejor manera de presentar lo que queremos entender aquí en el concepto de sublimación cultural sea volver a y comparar con la sublimación según Nietzsche y Freud, luego a y con el concepto de la aculturación de Brague y por último la noción que aquí proponemos.

En efecto, el concepto de sublimación se remonta a Humano, tan bumano (1886) del pensador alemán. Su concepto de la sublimación proviene de su teoría de los instintos, la cual representa su teoría del hombre, su antropología. Se puede decir lo mismo de Freud, aunque la teoría del instinto y la antropología de estos dos autores difieran fundamentalmente, al tiempo que poseen propiedades comunes. $\mathrm{Al}$ principio de Humano, tan humano, Nietzsche describe la sublimación de la siguiente manera:

[...] según su explicación [la de la filosofía histórica, basada en los métodos filosóficos de la ciencia natural], no hay, en sentido estricto, ni conducta no egoísta ni contemplación enteramente desinteresada; ambas son solo sublimaciones, en las cuales el elemento fundamental parece casi volatilizado y solo revela su presencia a una observación extremadamente fina. - Todo lo que necesitamos, y que puede sernos otorgado por primera vez, gracias al nivel actual de las ciencias particulares, es una química de las representaciones y de los sentimientos morales, religiosos, estéticos, así como de todas esas emociones que sentimos en las grandes y pequeñas relaciones de la civilización y de la sociedad, incluso en el aislamiento: ¿y qué pasa, si esta química llega a la conclusión que también en ese dominio los más magníficos colores están hechos de materiales viles, hasta despreciados? ¿Habrá mucha gente que tenga placer en seguir tales investigaciones? La humanidad prefiere expulsar de su pensamiento las cuestiones de origen y de comienzos: ¿no hay, acaso, que estar casi deshumanizado para sentir en sí mismo la tendencia opuesta? (Nietzsche, 1906, p. 21).

El concepto nietzscheano de sublimación, como se lo entiende aquí, hace uso de "una química de las representaciones y de los sentimientos 
morales, religiosos, estéticos, así como de todas esas emociones que sentimos en las grandes y pequeñas relaciones de la civilización y de la sociedad" (Nietzsche, 1906, p. 21). Es posible que esas ideas no sean totalmente identificables y algunos vean en ellas una prefiguración de una forma de la antropología evolucionista (Sperber, 1985; 1998; 2011): el individuo no es un hecho, es el resultado de una evolución natural, inconclusa por principio, producto de una "química de las representaciones y de los sentimientos humanos" (Nietzsche, 1906, p. 21). Con su ironía tan singular, Nietzsche (1996) señala que, al desarrollarse en la "sublimación”:

[...] el elemento fundamental [de la conducta moral humana] parece casi volatilizado y solo revela su presencia a una observación extremadamente fina [y quizá habría] que estar casi deshumanizado para sentir en sí mismo [esa] tendencia [hacia lo que llama la filosofía histórica] (Nietzsche, 1906, p. 21).

En el aforismo siguiente del mismo libro, el autor pone de manifiesto lo que llama "el pecado original [sic] de los filósofos":

PECADO ORIGINAL DE LOS FILÓSOFOS - Todos los filósofos cometen esa falta común, el de hablar del hombre actual y hacer su análisis piensan alcanzar la meta. Involuntariamente, "el hombre" se les aparece como una ceterna veritas, como un elemento fijo en todas las agitaciones, como una medida asegurada de las cosas. Pero todo lo que el filósofo enuncia sobre el hombre, en el fondo no es más que un testimonio sobre el hombre de un espacio y de un tiempo muy restringido. La falta de sentido histórico es el pecado original de todas las filosofías; muchos hasta toman sin saberlo la forma más reciente del hombre, tal como se produjo bajo la influencia de religiones determinadas e incluso de acontecimientos políticos determinados, como la forma fija de donde hay que partir. No quieren saber que el hombre, que la facultad de conocer, es también el resultado de una evolución; mientras que algunos de entre ellos incluso hacen derivar el mundo entero de esta facultad de conocer (Nietzsche, 1906, pp. 23-24). 
Parece que la carga polémica se deslinda con dificultad del análisis; sin embargo, tal vez podamos reconstruir nuestra discusión y entender mejor al confrontar con el discurso nietzscheano. Las ideas y los sentimientos humanos solo son sucedáneos químicos: las sublimaciones así concebidas no son más que una operación química que explica lo que se entiende, de acuerdo con los prejuicios filosóficos habituales, por "conducta no egoísta o contemplación desinteresada". Si reproducimos falsamente este tipo de prejuicios, es porque somos víctimas de un pecado original: "La falta de sentido histórico es el pecado original de todos los filósofos".

[Los filósofos] parten del hombre actual y al hacer su análisis, piensan alcanzar la meta. Involuntariamente, "el hombre" se les aparece como una aterna veritas, como un elemento fijo en todas las agitaciones, como una medida asegurada de las cosas. Pero todo lo que el filósofo enuncia sobre el hombre, en el fondo no es más que un testimonio sobre el hombre de un espacio y de un tiempo muy restringido (Nietzsche, 1906, pp. 23-24).

Para la intención de esta presentación, pensamos que el concepto de sublimación cultural llega a protegerse, de la crítica nietzscheana: en la medida en que es una prefiguración del concepto de skhole de Bourdieu, parece que la sublimación cultural y la vía romana se salvan tanto de la carga bourdiesiana de la "crítica de la razón escolástica" como de la de Nietzsche contra la "falta de sentido histórico", que el sociólogo francés habría retomado a su cargo. Sin embargo, con seguridad nuestro discurso propone aportar y apropiarse de una crítica constructiva que se vale tanto de una firme distancia como de una familiaridad no complaciente con las tres perspectivas — la "química de las representaciones", la "sociología crítica de la dominación” y la teoría freudiana de la libido y de los instintos-. La sublimación cultural pretende tomar contribuciones de cada una, pero con un curso propio, de la mano de la vía romana.

¿Qué dice Freud que sea diferente de Nietzsche? Es claro que para entender al pensador vienés es indispensable, sobre todo para su 
concepto de sublimación, conocer la influencia del autor de Humano, tan bumano y de la Genealogía de la moral (Assoun, 1998; Gemes, 2009).

La sublimación nietzscheana, en cierto sentido, no es más que un desplazamiento químico de los instintos. Si el instinto nietzscheano es el principio supremo de la vida, la "voluntad de poder", se debe entender la palabra sublimación como la forma degradada de la humanidad o como la forma inferiormente evolucionada del devenir humano a la espera de una forma viviente superior sin necesidad alguna de sublimarse, puesto que esta solo viviría del instinto de poder; por ejemplo, el "superhombre", el hombre que se supera a sí mismo en una nueva forma de vida que, desde entonces, ya no sería humana sino otra cosa.

Como lo señala Gemes (2009), la idea de Nietzsche saca provecho de una unificación en el orden de los instintos: hay una jerarquía explícita de los instintos, en la que la cumbre de la pirámide, su estado químico puro, está constituido por el instinto de dominación, que estructura y ofrece una comprensión organizada de los instintos que se derivan de ese instinto supremo. El superhombre sería así el ideal del ser que solo vive por y para ese instinto de poder.

La idea de naturaleza del pensador alemán está aquí cercana de la de Freud, pero es muy diferente de la de Marco Aurelio. Para este último, obedecer al mandamiento de la naturaleza significa devenir verdaderamente en sí mismo, un ser verdaderamente humano: se trata de la idea antigua estoica de naturaleza, que es normativa y se concibe como cumplimiento y ejemplo para la buena vida humana. Nietzsche es, sin duda, el pensador que ha destruido de modo más sistemático la concepción del hombre que el gran pensador estoico hacía suya. Vemos cómo las ideas de naturaleza y de lo humano están estrechamente ligadas entre estos autores. La noción freudiana de sublimación se inscribe en un proyecto terapéutico. Así, las "enfermedades" y los "pecados" que Nietzsche llama a veces "metafísicos" se convierten en las patologías cotidianas y comunes que producen las neurosis.

Aunque hay varias versiones de los conceptos freudianos, una pesimista y otra optimista en cuanto a las posibilidades de la cura, elegiremos 
para nuestro propósito una menos sombría de la teoría freudiana de los instintos y de la libido. La sublimación sería concebida como la transformación de la energía bruta de la libido en energía inspiradora de conductas de valor superior: arte creador, fe religiosa activa, fervor de trabajo. Suele resultar de la cura psicoanalítica, de modo que debe ser distinguida de la idealización, proceso más o menos narcisista que enmascara, sin transformarla, la energía pulsional (Freud, 1973, pp. 243-247).

Según Freud, dos grandes principios se encuentran en el origen del comportamiento humano, idea desarrollada a lo largo de toda su obra, en particular en Más allá del principio del placer, Cinco lecciones sobre el psicoanálisis y Malestar en la cultura: el principio de placer y el principio de realidad. El ser humano está sometido a la necesidad de sus pulsiones arcaicas; la única manera que tendría para hacerse una persona libre sería por medio de la toma de conciencia de las causas de su acción, es decir, de las pulsiones profundas que le hacen actuar de una manera. En el fondo de las pulsiones que nos animan está la potencia enigmática del inconsciente, lleno de contradicciones y de tensiones, que anima a nuestro ser por y con fuerzas involuntarias de acción, pensamiento y amor.

El principio de realidad es aquello contra lo que debe confrontarse inevitablemente el principio de placer: tarde o temprano, en la vida de un individuo los instintos sexuales se enfrentan al contacto con lo real, que frustra, reprime o frena al poner obstáculos al carácter ilimitado de la búsqueda instintiva del placer. Lo real, definido de modo negativo, sin descripción ontológica, se expresa como lo que marca límites al placer, lo que se opone o, más bien, no es el placer en sí mismo, sino una lucha del instinto (o del principio del placer) contra lo real, que no le permite desarrollarse indefinidamente.

La experiencia de lo real y de los límites elevados ante el placer es antropológica fundamental. La manera en que el individuo lo haga, lo convertirá en un sujeto libre o esclavo con respecto a la violencia incontenible de sus instintos. La liberación absoluta no solo es imposible: tampoco es deseable. 
El determinismo panpsíquico y pansexual de Freud —la idea según la cual hay un aspecto irresistible e inevitable en las fuerzas del inconsciente que nos empuja a actuar como lo hacemos sin libertad de actuar- está matizado por la noción muy particular y fecunda de sublimación de las pulsiones.

La sublimación es un proceso que se hace con el trabajo sobre el inconsciente al término del y durante el análisis. Este último, sin embargo, no debe hacerse solamente con el analista, sino que puede y debe hacerse también a lo largo de toda la vida, cuando ese proceso de trabajo sobre sí mismo tiene lugar. La sublimación, en tanto proceso indeterminado y abierto, recubre y retraduce el sentimiento de determinismo duro de la teoría de las pulsiones inconscientes. Esto no ocurre mediante la eliminación de dichas pulsiones o de su recubrimiento bajo una personalidad nueva, sino más bien por una retraducción en un nuevo orden que supera el interés instintivo egoísta en un nuevo orden, para hacer de este algo útil, hermoso y grande o también para la búsqueda de lo verdadero y, aún mejor, algo sano. La sublimación es una progresión nunca terminada, que hay que rehacer, recrear y que es creadora, formadora y realizadora de personalidad.

Si un individuo animado de una economía pulsional muy poderosa y caracterizada por la agresividad de pulsiones que de niño fue motivado a actuar de manera sádica con un animal y mutilarlo, llegase a una forma de sublimación psíquica de sus pulsiones inconscientes, podría, por ejemplo, ser un cirujano en vez de un asesino serial. La economía de las pulsiones de agresividad ya no se dirigiría a causar daños a los otros o a sí mismo, sino que ahora ejercería una actividad motivada por la agresividad y la potencia de las pulsiones, pero controlada y dominada en el marco de una causa no perjudicial e incluso, en resumidas cuentas, muy útil para los otros:

La sublimación de los instintos constituye uno de los rasgos más destacados de la evolución cultural; es ésta la que permite a las actividades psíquicas elevadas, científicas, artísticas o ideológicas, de desempeñar un papel tan importante en la vida de los seres civilizados. A primera vista, estaríamos tentados de ver en esto 


\section{8 / Asher GUtKind}

esencialmente el destino mismo que la civilización impone a los instintos. Pero haríamos mejor de reflexionar más al respecto. En tercer lugar, finalmente, y este punto parece el más importante, es imposible no darse cuenta en qué gran medida el edificio de la civilización se basa en el principio de la renuncia a las pulsiones instintivas, y a hasta qué punto la civilización postula precisamente la no-satisfacción (represión, supresión o algún otro mecanismo) de instintos poderosos. Esta "renuncia cultural" [En el texto, "Kulturversagung", es decir más exactamente la negativa de la civilización (a dejar al individuo satisfacer los dichos instintos). (N.d.T.)] rige el vasto dominio de las relaciones sociales entre humanos. Y ya sabemos que en esta negativa reside la causa de la hostilidad contra la cual todas las civilizaciones tienen que luchar (Freud, 1989, pp. 27-28).

¿Freud acaso se aventuraría a decir que la sublimación es buena? Sin duda podemos rechazar esta idea en su sentido moral. Habría que tomarla quizás en su "sentido extra-moral", que propuso el inspirador del concepto de sublimación: el autor de Humano, tan bumano. Positivista, el doctor vienés no creía en ese tipo de nociones morales como algo bueno.

La sublimación es un estado posible del sujeto para llegar a ser sujeto; esto también quiere decir llegar a ser una persona capaz de gobernar (en el sentido pragmático) su economía pulsional y las patologías que le imponen una vida de sufrimiento, de desconexión con lo real o, de manera más tajante, de perturbación psíquica. Así, la sublimación es, finalmente, el proceso de cura de la personalidad que permite encontrar y vivir lo real, lo que para Freud significa civilizar al individuo o el individuo que se civiliza. Las pulsiones inconscientes están constituidas de todos esos tipos de obstáculos más o menos duros, de diversos grados y formas, que impiden ser sujeto.

Esta noción se entiende de manera siempre negativa como el estado individual, en constante hacer y rehacer, crear y recrear, de una per-

2 Nietzsche, F. ([1873] 2009). 
sona que vive en vista del gobierno de su economía pulsional, gracias al trabajo y al proceso de sublimación. Este proceso permite al individuo hacerse sujeto, "más allá del principio de placer", camino por el cual adapta sus instintos a otro principio, el "principio de realidad": esto le permite y lo obliga a confrontarse con lo real sin pasar ni causar demasiado sufrimiento y superar las dicotomías entre instintos sexuales de placer y choque con lo real. Sin embargo, no se trata de abolir el deseo, pues sin él ni siquiera podríamos soñar con ser, hacer, pensar, producir, amar: el caballo de Schilda moriría inevitablemente, para reutilizar la fábula que Freud cuenta en conclusión de su quinta lección de psicoanálisis de 1909:

He aquí por fin la tercera de las conclusiones posibles del tratamiento psicoanalítico: es legítimo que cierto número de tendencias libidinales reprimidas sean directamente satisfechas y que esta satisfacción sea obtenida por los medios comunes. Nuestra civilización, que aspira a otra cultura, hace en realidad la vida demasiado difícil a la mayoría de los individuos y, por el miedo de la realidad, provoca neurosis sin tener nada que ganar con este exceso de represión sexual. No descuidemos por completo lo que hay de animal en nuestra naturaleza. Nuestro ideal de civilización no exige que se renuncie a la satisfacción del individuo. Sin duda, es tentador de transfigurar los elementos de la sexualidad por medio de una sublimación cada vez más extensa, para mayor bien de la sociedad. Pero, así como en una máquina no se puede transformar en trabajo mecánico utilizable la totalidad del calor gastado, tampoco se puede esperar a transmutar totalmente la energía proveniente del instinto sexual. Esto es imposible. Y al privar al instinto sexual de su alimento natural, se provocan consecuencias negativas. Recuérdese la historia del caballo de Schilda. Los habitantes de este pueblo tenían un caballo cuya fuerza producía su admiración. Desgraciadamente, el mantenimiento de la bestia costaba muy caro; se resolvió, para acostumbrarlo, a estar sin alimento, disminuyendo cada día de un grano su ración de avena. Así se hizo, pero cuando se retiró el último grano, el caballo estaba muerto. La gente de Schilda nunca supo por qué. Por mi parte, me inclino a creer que 
murió de hambre, y que ningún animal es capaz de trabajar si no se le proporciona su ración de avena (Freud, 1965, p. 41).

La sublimación propone e impone la vía de nuestra humanidad civilizada según Freud, pero no se puede pretender eliminar el instinto (de vida), el principio del placer: eso significaría nuestra muerte. Existe una fuerte tensión entre los procesos civilizadores contenidos en nuestras aptitudes para la sublimación de nuestros instintos y el peligro de llevar tan lejos (o de manera tan errónea) el proceso que tiende a eliminar todo deseo o instinto, lo cual nos pondría en peligro de muerte. Civilizar el instinto es equivalente de simbolización, "psiquización", volver cultural un fenómeno subterráneo, mientras que querer eliminar todo instinto es sinónimo de peligro de extinción o agotamiento del deseo de vida.

Parece que Freud recuerda una idea estoica, quizás en discusión indirecta con ideas neoplatónicas, que está formulada por Marco Aurelio (1992) en el siguiente aforismo: "lo que [el hombre] hace no es un mal [...] [si] no hace un trabajo contrario a su naturaleza":

El trabajo de la mano o del pie no es contrario a su naturaleza, mientras el pie haga sólo la función del pie y la mano la función de la mano. Del mismo modo, el hombre, como hombre, no hace un trabajo contrario a la naturaleza mientras hace lo que el hombre debe hacer. Y si no es contrario a su naturaleza, lo que hace tampoco es para él un mal (p. 57).

Miller explica que, a pesar del carácter problemático de la noción, la sublimación se refiere a algo real, que indica un movimiento y no un resultado:

La sublimación es un movimiento más bien que un resultado, movimiento de transformación, de cambio de estado y quizás el movimiento mismo de la transformación pulsional. La sublimación me parece mejor definida como proceso que como producto, aunque Freud siempre ha insistido en la producción de objetos culturales que se pueden compartir, esencialmente creaciones in- 
telectuales o artísticas. En este sentido, la sublimación sería uno de los aspectos — ¿el más "elevado"? — de lo que especifica el devenir psíquico como transformación de la excitación a partir del anclaje biológico. Este modelo de un movimiento de transformación hacia una psiquización cada vez más importante no concierne sólo al destino psíquico del ser humano, sino también a la evolución de la cura, al de la civilización y al desarrollo del psicoanálisis (Miller, 1998, pp. 1049-1050).

Miller muestra que, a pesar de su aspecto problemático, en el pensamiento freudiano de la sublimación reside algo fundamental, una "realidad psíquica innegable", que es también una transformación de la pulsión instintiva en movimiento de cura y de cultura, los cuales parecen dos movimientos de un mismo proceso. Es por eso que quise reunir varios conceptos y transformarlos en esta idea de sublimación cultural, en particular, la aculturación positiva y la cultura excéntrica, la sublimación freudiana y la skhole como sociología de esta aptitud: la sublimación cultural, así entendida, pretende ser sobre todo una reformulación transformadora, que prosigue para nuevas vías con la ayuda de reinterpretaciones de las perspectivas de Freud, de Bourdieu y de la teoría de la cultura de Brague, resumida en su concepto de "vía romana".

\section{Bourdieu y la skhole. Una sociología historicista- agonística de la emergencia de lo universal}

La sociología de la skbole de Bourdieu (1982; 2003) quita las máscaras del punto de vista escolástico. En efecto, cierta visión idealizada de la ciencia y de la razón puede inclinarnos a pensar que lo racional, lo científico y lo universitario se sitúan fuera de lo social y de la historia, inmunizada frente a las luchas, las contradicciones y la urgencia que constituyen lo propio del mundo de lo social: el sabio y el intelectual estarían sin ataduras, sin relación con los antagonismos sociales y políticos propios a los humildes mortales. Ahora bien, la sociología es un gran emprendimiento para desenmascarar esta "visión escolástica" de una posición falsamente universal. Está basada en una historia y una sociología particulares que, paradójicamente, hacen posible la producción de lo universal. 
La empresa bourdiesiana de demolición de las máscaras se configura como heredera de dos siglos bien sólidos de "deconstrucción", en el sentido que aquí le damos: hacer caer las máscaras. Bourdieu (1982; 2003) afirma que existen condiciones históricas y sociales para que un espacio social, la skhole, facilite una producción de valor y de interés por la verdad. Esta visión desenmascara la ilusión intelectualista e ingenuo, la illusio del campo científico, quita la hipocresía de la "razón escolástica", entendida como un deseo del individuo de poder usar su razón como si no perteneciese al mundo social, incluso como si no perteneciese al mundo. Mas, según Bourdieu, así como no hay mente pura tampoco hay ideas puras: "Hay una historia de la verdad. Esto no significa necesariamente que la razón se reduzca a su historia sino que hay condiciones históricas y sociales de aparición de formas sociales de comunicación que hacen posible la producción de verdad" (Bourdieu, 1982, pp. 43-44).

Es por eso que existe una condición humana para desear, producir y reproducir lo universal, según la sociología historicista-agonística de la emergencia de lo universal, la skhole: "Es al descubrir su historicidad que la razón puede darse los medios para escapar de su historia" (Bourdieu, 1982, p. 39).

La radicalidad de su análisis sociohistórico del campo científico adquiere mucha más claridad e inteligibilidad si entendemos que se desarrolla en un movimiento de pensamiento dialéctico.

Recordemos: la skbole se ha hecho posible en una historicidad, un estado social, un estado psíquico particular, la libido sciendi, el habitus formado por y formador de la institución social de la skhole, el campo científico. Esta institución sociohistórica es la condición que permite la existencia de peleas reguladas por la investigación agónica, competitiva y nunca terminada de la verdad; las luchas de competencia por la prueba o la idea prevalente sobre la otra; un arte marcial para tener la última palabra, por medio de códigos inéditos en la historia humana; esto consiste en el hecho de buscar un mejor argumento que el otro y en la aceptación provisoria, siempre parcial y revisable, del argumento "ganador" del momento, temporal y circunscrito en un 
lugar cuyo medio tan específico imprime a la fricción de las ideas de los pares una institución de lo social de esa manera singular de vivir para la búsqueda racional: todo esto sería la skhole.

Pensamos que, de modo paradójico, la skhole es la precondición de lo universal y que, así, la sociología historicista-agonística de la skbole asienta los fundamentos explicativos y también normativos de la emergencia y de la práctica de lo universal.

Según las interpretaciones relativistas y particularistas, lo universal es, en sí mismo, una creencia falsa; sugieren que no hay algo universal, verdad, argumento o idea que esté mejor fundado que otros: toda verdad lo es por su poder social y cultural, por su "hegemonía cultural", su "dominación social": la interpretación relativista concluye que, en sentido literal, no hay verdad.

En su teoría de la skhole, sin embargo, existen "progresos de la razón", que se hacen según ciertas condiciones, destinada a ciertos agentes, por medio de intereses particulares, en un tiempo y un lugar singulares, bajo forma irreconocible para una visión tradicional. Porque, de manera desencantada, sin veleidad de historia universal en sí, consideramos que Bourdieu propuso una teoría fuerte de lo universal, una teoría sociológica no-relativista y realista de la investigación racional.

\section{La vía romana: la idea de Europa como idea de la cultura}

Brague, por su parte, discute los fundamentos y la constitución de la idea cultural europea. ¿Qué es lo que hace que Europa sea Europa y no otra cosa? ¿Puede dejar de serlo? ¿Lo fue siempre? ¿Cómo podemos afirmar legítimamente lo que Europa es y lo que no es? Podemos comenzar, dice el autor, por delimitar sus contornos físicos: geográficos, demográficos, climáticos, geológicos, históricos, lingüísticos: "Este pequeño cabo de Asia", esta coma rara entre África y Asia pegada al océano Atlántico, la punta improbable de un continente asiático mucho más vasto y más distintamente recortado.

¿Qué es Europa en su existencia propia? Tal vez haya que emplear una vieja palabra que tiene pertinencia a pesar de las destrucciones 
conceptuales sucesivas: ¿Europa sería una conciencia? Así como lo proponía Ernest Renan (1882) para definir lo que podría ser la Nación de Francia, sería interesante utilizar su fórmula: Europa sería así un plebiscito de las voluntades europeas que debe ser renovado cada día para seguir siendo tal. Mas ¿continuar siendo qué? Antes de entrar en materia para aportar una respuesta sustancial, atengámonos por el momento a esta definición o constatación formal y veamos lo que se opone a la clara comprensión de lo que es Europa.

Las corrientes intelectuales y morales que surgen como objetivo el proyecto de acabar con la cultura europea existen y se desarrollaron desde los orígenes de la cultura europea. Sin embargo, se trataba de críticas internas, de ajustes de cuenta nacionales y políticos, de kulturkampfen el seno del desarrollo de las Naciones y de las épocas culturales nacientes en Europa. Para citar algunos de los grandes nombres de la historia intelectual europea, la crítica antimoderna (y a veces antioccidental) se desarrolló desde el primer romanticismo alemán hasta, por ejemplo, las teologías políticas anarquistas de Taubes (2009) y Agamben (1997) y pasó por Nietzsche y el pensamiento eslavófilo.

Queremos señalar que la crítica antimoderna, que hoy parece identificarse cada vez más con las formas diversas y variadas de la crítica antieuropea, no data de ayer y no esperó la emergencia de los estudios culturales y de los estudios de subalternización en el campus de Cambridge; no esperó que en los campus estadounidenses se denunciara el "eurocentrismo", la "hegemonía cultural hemisférica del Norte" (de hecho, de Europa) sobre toda forma de saber, incluida la histórica y la filosófica e hiciera caer la sospecha y la desconfianza (que se dice "epistemológica") sobre todo el saber. Es posible concebir la crítica poscolonial —que solo indico, pues su discusión merecería todo un ensayo, que desearía proseguir en un proyecto más amplio sobre sublimación cultural - como una especie de radicalización o, tal vez, una exageración de la antigua crítica nacida de las ciencias sociales: lo que Manent (1994) ha llamado el "punto de vista histórico" y el "punto de vista sociológico".

Para pensar el problema de la cultura, podemos considerar que, según el punto de vista sociológico, la vida intelectual se reduce a sus 
circunstancias históricas y sociales de enunciación y de aparición. A diferencia de cierta creencia contemporánea, no es un punto de vista nuevo. Como ya mencionamos, el historicismo alemán del siglo XIX y la nueva ciencia histórica que apareció alrededor de 1800, con las figuras de Humboldt, Ranke y Hegel, en diversos grados relativamente radicales y definitivos, habían sentado las bases de estos principios: las ideas, las creencias, las religiones, los códigos morales y de conducta, la organización jurídica, el pensamiento político y las formas de producción de la verdad, estaban pensados según las circunstancias históricas y sociales de su aparición. Deberíamos volver, sin duda, a Michel de Montaigne o hasta al gran Bartolomé de Las Casas para observar, bajo una forma sistemática, profunda y radical, este tipo de ideas que la noción demasiado general de relativismo cultural no expresa con suficiencia.

La teoría del eurocentrismo se inscribe en una larga historia de pensamiento. No es, en definitiva, de otra cosa que de la voluntad de historizar, de sociologizar y de relativizar las ideas, pero en este caso, parece que se trata de una radicalización fuerte: se ataca en bloque a la totalidad de la historia europea, a partir de la idea de que impuso por la fuerza una hegemonía cultural y para servir sus intereses imperialistas, primero en sus imperios coloniales, en sus zonas de influencia comercial y, por último, en el mundo globalizado, entendido como occidentalizado o eurocéntrico.

La crítica del eurocentrismo no solo se refiere a los diversos daños debidos al desarrollo cada vez más extenso de la fuerza de las potencias europeas, sino que además ataca la cultura misma, su literatura, su arte, su filosofía, su pensamiento, su saber; la noción de "epistemología colonial", la noción de "epistemología del Sur" o "epistemología de los oprimidos" que parece equivalente, propuesta, por ejemplo, por De Sousa Santos (2009), se han vuelto comunes en los estudios poscoloniales y los estudios subalternos, en particular. Si estas proponen nuevas ideas, para pensar de nuevo la idea de Nación, ${ }^{3}$ estas nociones

\footnotetext{
3 Para leer un balance interesante de estas corrientes de estudios, en especial sobre la teoría de la Nación, puede verse Dube, S. (1999).
} 
no tratan de las imposiciones de normas mongoles, árabes, persas o chinas: solo se ocupan de los europeos.

Sin duda, gran parte de este discurso adquiere fuerza persuasiva porque se basa, en parte, en argumentos históricos. Europa occidental dominó al mundo o a una buena parte de él durante varios siglos, digamos entre el siglo XV y principios del siglo XX. Si se considera a Estados Unidos como una Nación occidental, entonces están incluidos en la carga crítica. En cambio, si el proyecto estadounidense se vuelve a pensar según nuevos fundamentos no eurocéntricos, entonces se salvan de la crítica. Es notable, me parece, que estas corrientes de pensamiento violentamente críticas de los legados europeos provengan del subcontinente norteamericano: ¿Los Estados Unidos querrían acaso salir de Occidente o bien querrían hacer salir a Europa de la civilización, al mostrarla como indeseable? Es útil y beneficioso, de todos modos, recordar episodios desgraciados, nefastos, criminales o dramáticos por razones diversas de la historia, para poner de relieve el importante papel desempeñado por las potencias europeas.

Sin embargo, creemos que una cosa es recordar y describir concienzudamente hechos lamentables y condenables o acciones históricas europeas que han provocado desastres y catástrofes, por la razón que sea, de modo directo o indirecto, por causa formal o secundaria de la acción europea: esta crítica histórica, sociológica y política es legítima, buena y necesaria, pero otra cosa es definir la esencia del proyecto de la cultura europea como de naturaleza colonialista, imperialista, depredadora y hegemónica, que da lugar a los movimientos de hegemonía cultural global de naturaleza, de origen y de esencia europea: en otras palabras, otra cosa es querer mostrar el proyecto europeo como la expresión de la sola voluntad de poder — como quizá lo habría celebrado Nietzsche, autor que muy a menudo representa una referencia importante, cuando no fundamental, para la mayoría de este género de estudios- Sobre la recepción de Nietzsche en Francia y su influencia sobre los intelectuales que más tarde serán nombres de autores por excelencia de la crítica posmoderna, remitimos a los trabajos interesantes de Pinto (1995). 
Si la detracción poscolonial o subalterna del eurocentrismo se instala en una crítica de fenómenos empíricos que evidencian manifestaciones de imposición de una cultura a expensas de los indígenas, en circunstancias históricas particulares, entonces esto entra en la lógica de la investigación científica y debe ser examinado de ese modo, pero pasar de esta postura histórica y científica de una reducción esencialista del proyecto europeo a la voluntad de poder, y la ejecución de una dominación universal sobre cualquier otro tipo de cultura, que debe ser eliminada para que la cultura hegemónica se extienda a todo lo real, existe una frontera trasladada que no nos parece legítima.

En efecto, pensar que el hecho de que la fuerza haya pertenecido durante muchos siglos a las entidades políticas europeas y que esta - como Fuerza ante todo y no tanto en calidad de titular de la marca Europa - se haya impuesto en numerosos territorios y poblaciones sea la característica esencial de esta cultura europea, parece ser una falacia, porque toda cultura que haya poseído la fuerza quiso imponérsela a los demás: desde los griegos de Alejandro Magno a los mongoles de Genghis Khan. Toda cultura que tuvo fuerza trató de asentarla y continuará haciéndolo. Podríamos llamar a este fenómeno el maquiavelismo esencial de las culturas humanas.

Ahora bien, nuestra propuesta se basa en la observación de dos cosas interdependientes: 1) La primera es que el orientalismo, si se admite que existió o que continúa existiendo, se ha hecho posible gracias al deseo de descubrir al otro. Si a veces este deseo puede haberse desviado o mal terminado en una voluntad de dominación y de conquista, con un "encubrimiento del Otro" (Dussel, 1992), la curiosidad europea es difícilmente discutible; 2) La segunda es que el hecho representativo de la cultura europea, sus facultades autocríticas, son las condiciones de una revisión personal de sus creencias y prácticas propias, sobre todo de tal violencia, como lo representa la de Edward Said y otros cercanos a esta inspiración. No se trata de negar las inclinaciones dominadoras y conquistadoras en la historia y la civilización europea, sino de no reducirla a ellas. Se propone no olvidar que, si realmente existe una especificidad europea, esta no reside tanto en esos hechos amargos que son comunes a todas las civilizaciones que dominaron 
o lo están haciendo, sino al contrario: al hecho único de acoger y de producir autocrítica, incluso de ponerla en el centro de sí, como una facultad fundadora, creadora y positiva. Esta propuesta incorpora un movimiento intelectual y se inscribe en un mosaico de perspectivas de comprensión de lo propio de Europa al que con este mismo escrito se espera ofrecer un pequeño aporte (Castoriadis, 1996; Kolakowski, 1986; Lévinas, 1976; Voegelin, 1952; Manent, 1994; 2010; Bouveresse, 1984; Brague, 1998; 2009a).

Sin embargo, el proyecto de civilización se sitúa —es nuestra propuesta - en un proceso de educación de la conciencia de sí y del otro. La vía romana es la imagen que da Brague para ilustrar el proyecto cultural europeo, la forma de cultura de Europa, en el sentido de una posibilidad contenida en su esencia, que también debe estar contenida en potencia para hacerla existir. Por ejemplo, las instituciones, las voluntades individuales y las voluntades del pueblo son necesarias para hacer existir a Europa, es decir, su forma cultural. La idea de la cultura debe estar contenida en acto, debe hacerse de manera permanente por las personas, a riesgo de desaparecer.

La teoría cultural de la vía romana de Brague se basa en un concepto fuerte de la responsabilidad, del deber y del actuar humanos. Afirmamos - es nuestra propuesta conceptual — que se trata de un proyecto de sublimación cultural, que detallamos en este ensayo.

La vía romana se caracteriza por una concepción y una práctica cultural según la cual la "vía del Señor" no es un camino escrito por anticipado, sino una aventura del Verbo, en la que nada se garantiza sobre lo que Dios dijo. Esa idea de Dios supone que el contenido fijo y determinado de su palabra está en manos del camino indeterminado del ser humano, a quien Dios no le dictó de antemano lo que él debe ser y lo que debe conocer. Los caminos de la teología (Brague, 1998; 2005; 2008), en el sentido de un Dios que habla a los hombres de persona a personas y opuesto al sentido de la voluntad de un Dios que impone su ley a los individuos (teonomía), representa la concepción de la ley divina que triunfó en la cultura filosófica latina cristiana y judía. Esta vía romana habría hecho posible la libertad de filosofar. Brague dice 
esto apoyándose, por una parte, en un análisis sociológico y muestra que el estatuto social de la filosofía no es el mismo en cada una de tres culturas medievales: árabe, hebrea y latina (Brague, 2008).

Sostiene que solo la cultura latina cristiana y judía hizo posible un ejercicio libre de la filosofía, gracias al estatuto social concedido a los filósofos en las universidades latinas, ejemplo inédito hasta entonces de ejercicio de esta actividad. Por otra parte, esta institución - las universidades latinas - fue creada y consolidada en ese momento de la historia humana y de la Edad Media hacia los siglos XII y XIII en Europa latina. Añade que la creación social de esta forma institucional de ejercicio del saber contribuyó a seguir modelando este "método de hacer cultura" inventado en Europa, con más precisión en Roma, en sus premisas históricas, que también se denominan en francés "cultura" a secas.

$\mathrm{Al}$ análisis sociológico (el que se refiere a las condiciones sociohistóricas de posibilidad de emergencia de un mundo social y de una historia que llama la romanidad) se suma el análisis psíquico (la secundariedad, el complejo positivo de inferioridad, el modo de apropiación, la inclusión), luego el análisis cultural (la relación cultural y la cultura como trabajo sobre uno mismo e ideal de humanidad) y a este un análisis religioso.

Brague piensa que en el seno del Nuevo Testamento, de la tradición de los padres de la Iglesia y de la historia cristiana la relación de lo práctico y lo religioso se constituyó de manera específica y única. Gracias al conflicto dialéctico entre el Imperio y la Iglesia en Roma cristianizada - en particular desde el edicto de Teodosio, obispo de Roma, en el que la Iglesia reivindicó el monopolio de la esfera espiritual— así como en el momento de las persecuciones del Imperio contra los primeros cristianos, las esferas profanas y espirituales han sido dos dominios distintos que permitieron el surgimiento de la cultura. A pesar de las tensiones perpetuas y las intromisiones incesantes que reaparecen de repente, la religión nunca invadió por completo el terreno de la filosofía, mientras que la filosofía no invadía (todavía) por completo el terreno de la religión; sin fundirse uno con otro o destruirse. Todo esto hizo posible la cultura. 
La romanidad, es decir, Europa latina, es este fenómeno humano que funda y construye poco a poco las condiciones de posibilidad sociológicas, culturales, religiosas y políticas para la emergencia de una verdadera libertad de filosofar y en su sentido francés, el nacimiento de la cultura (Brague, 2009a).

\section{La sublimación cultural. Pedagogía del trabajo sobre sí mismo y del trabajo de la conciencia}

He aquí por qué parece que la cultura así definida es el proceso y el proyecto pedagógico y cultural que permite extraerse a conciencia de sus pulsiones arcaicas. La sublimación cultural consistiría en el impulso cultural de acceder y vivir para lo universal, únicamente posible gracias a una educación de la conciencia de sí mismo. Para eso hay que saber trabajar sobre el inconsciente esencialista, atravesado por la idea de que "mi cultura es primera, todopoderosa", cuyos deseos - pulsionesson ilimitados y cuyo objetivo inicial, fundador y final, es sí mismo: sí mismo como una cerca de sí sobre sí mismo, cerca etnocéntrica, en un círculo perfecto que gira en su ritmo cósmico cíclico.

La teoría de la skbole de Bourdieu demuestra los fundamentos necesarios para que una cultura haga en ella un lugar a lo universal. Tal como la comprendemos, esta teoría analiza las condiciones debidas a la historia, a la cultura (en el sentido singular) y a la sociología de cada una de las culturas y aporta elementos útiles para articular la teoría de la vía romana. Según nuestra interpretación, la skbole no es otra cosa que la condición sociohistórica, etnohistórica, que posibilita dedicar su vida a lo universal. Así, si el punto de partida o, más bien, la condición material - la materia, en el sentido de los Antiguos- está constituido por condiciones sociohistóricas, políticas y culturales particulares (en el sentido indígena), la forma y el acto de dar existencia al proyecto cultural, bien que esté condicionado y muy bien explicado desde este punto de vista por la sociología así comprendida, no puede reducirse a ello y debe abrir camino para la comprensión de la aventura de la cultura. Pertenece a la dinámica de Occidente y repite una fórmula del sociólogo Elias (2012) o, como diría Braudel, a las estructuras de muy larga duración de la historia del pensamiento occidental. 
Pero ¿qué entendemos por cultura europea? Kolakowski (1986) definió bien el problema, nos parece, en lo que denomina su "eurocentrismo paradójico". ¿Acaso entendemos por cultura europea la posibilidad de adquirir el sentido de lo universal o bien se trata de tomar de ella las técnicas y saberes a fin de poseer y de aumentar su potencia política? Kolakowski piensa que Europa se define como poseedora de facultades autocríticas que le dan una capacidad singular para arrancarse a sí misma. Su universalidad es paradójica porque, en términos del polaco, es única, "superior", en el hecho mismo de que es única en su género, en su negativa a pensarse como superior, a pensarse como el centro y lo universal, criterio de toda cultura. Con demasiada frecuencia, cuando se piensa en las razones últimas del hecho europeo, pensamos en su fuerza. Eso bien podría ser el reflejo de su propia relación cultural: lo primero que el resto del mundo quiere de la cultura europea, son las técnicas militares, lo último, las libertades públicas, las instituciones democráticas, los criterios intelectuales (Kolakowski, 1986).

Kolakowski ha desarrollado una idea muy cercana de la vía romana, bajo la forma derivada que proponemos defender en este escrito: la de la sublimación cultural. En el siglo XIX, más recientemente a fines del siglo XX o a principios del siglo XXI, otros pensadores ya habían propuesto ideas parecidas — porque quizá no sean tan nuevas y originales - las ideas de recuperaciones intelectuales y morales que se imprimen y que proponen un renacimiento cultural. Kolakowski piensa, al igual que en la noción de cultura excéntrica, que Europa sería un espacio singular donde, de manera inédita en la historia de las culturas, se habría posibilitado la salida de la cerca etnocéntrica, la curiosidad de apertura a otras culturas y se habría descubierto la tesis de la unidad de la humanidad, del mismo modo que supo "descubrir" las religiones mundiales, primero en una toma de conciencia antropológica (Vitoria, Montaigne), luego en el desarrollo progresivo de un estudio, de una curiosidad moral e intelectual y por último, descubrir una ciencia, la filología de los textos sagrados y las ciencias de las religiones en general, gracias al "descubrimiento de la religión a la edad de la razón” (Stroumsa, 2010). Habría encontrado en ella misma una superación cultural única, porque el instinto de toda cultura es creer 
en su superioridad, en su universalidad, pensarse superior y mejor o por lo menos poseer, en parte, la característica del etnocentrismo. A la inversa, Europa no se hizo a sí misma bajo rasgos de identidad cerrados: se identificó por el movimiento de arrancarse a sí misma, de mirarse con los ojos de otros, de poner en tela de juicio su propia identidad y de manifestar una curiosidad indefectible con respecto a los demás: la especificidad europea no se encuentra en ningún otro lugar. Como se puede observar, según estos pensadores de los que repetimos, como podemos, un pensamiento común y una familiaridad mental, lo propio de Europa se identificaría en el extremo opuesto de aquello de lo que la acusa la crítica poscolonial. La pregunta que hoy se hace lancinante: “¿No es usted eurocéntrico?” Cuestión, de paso, planteada y replanteada a lo largo de la historia cultural europea, a menudo en forma de una autocrítica matizada o virulenta; la crítica posmoderna y poscolonial, subalterna, del Sur, contrahegemónica, viene del exterior o querría venir de un exterior, a veces imaginario (ya que hasta América Latina tiene muchos más rasgos europeos, en muchos sentidos, que indígenas). Es un debate amplio y complejo que necesita toda una vida de reflexión. Tal vez cuando Dussel (1992), desarrolla una crítica apasionante de la cultura como la negación del otro (encubrimiento del Otro), aunque su discurso sea a menudo muy pertinente y justo, sería aún mejor si volviera a la cultura latinoamericana en forma de autocrítica por ejemplo, esta tentación (quizá universal) de querer "lo mismo" en "el otro". Sobre este punto, Ricœur (1990) parece más pertinente, al hacer de él una tentación o una deformación identitaria, en absoluto propio de los europeos como tales o de su cultura, sino del individuo, en tanto posee inclinaciones egoístas y caducas sobre sí mismo.

Ahora bien, Castoriadis (1996) ha desarrollado, en toda su obra de madurez, una rica y fértil réplica que se parece tanto a la de Brague como a la de Kolakowski: la acusación o la autocrítica de eurocentrismo indica que hay personas europeas para plantearse la cuestión de la validez de su cultura, para aceptar la crítica y examinar sus propios defectos y las faltas cometidas. 
Manon explica uno de los hitos del problema planteado por el relativismo cultural y la respuesta de Kolakoswki:

¿Y entonces, la cultura que ha hecho posible la afirmación de una universalidad humana y de la igualdad de las culturas puede acaso sin contradicción afirmar la igualdad de todas las culturas, profesar un relativismo cultural y al mismo tiempo que se niega a denunciar la barbarie de los otros, deleitarse en ver la barbarie en ella exclusivamente? Kolakowski responde de manera clara a esta cuestión. El relativismo cultural es inconsistente. Europa no puede haber abierto un horizonte de universalidad sin estigmatizar lo que en los otros se escapa de la exigencia así formulada. No es que esta apertura deba significar uniformización y planetarización de un solo modelo cultural, sino superación de cada uno gracias a una tarea que, habiendo sido asignada a partir de un suelo particular, concierne sin embargo a todos los miembros de la especie humana. "El universalismo se paraliza a sí mismo si éste no se considera universal, es decir susceptible de ser propagado por todas partes" escribe Kolakowski en su conferencia: ¿Dónde están los bárbaros?: Las ilusiones del universalismo cultural. Dice aquí lo siguiente: "Esto presupone la creencia que ciertos valores de esta cultura - a saber sus facultades autocríticas - no sólo deben ser defendidos, sino también difundidos y también que, por definición, éstos no se dejan difundir por la violencia" (Manon, 2008).

$\mathrm{Al}$ igual que la idea de eurocentrismo paradójico y las reflexiones de Castoriadis, la noción de vía romana presupone, en la forma cultural europea, un proyecto, un proceso, un carácter no lineal y una filosofía crítica de la historia, una inscripción social e histórica de su identidad, de esa manera de-esencializada, así como una dinámica autocrítica, tanto respecto a sí misma en sus acontecimientos concretos, en particular los "lados oscuros" y los "libros negros" causados en su historia. No se reflexiona a menudo sobre el hecho de que la misma idea de un libro negro de... es una relación cultural europea en esencia, de la cual sería muy difícil encontrar rastros en otra civilización. Esta relación cultural es inherente a la definición de la identidad europea, según los términos aquí reutilizados: identidad excéntrica, vía romana, 
romanidad, secundariedad cultural y religiosa, el contenido de Europa es ser un contenedor estar abierto a lo universal; muchas fórmulas que tratan de acercar la singularidad de Europa, a la que en el fondo se hace el honor, de encomendar una tarea que es de cada individuo, en la medida en que la cultura es una tarea universal e infinita. Europa es presentada como un puente entre la barbarie y la civilización y la europeización, como asunto de todos, tanto de los europeos cuyo error sería creer que poseen lo que tienen que conquistar - como de los no europeos- cuyo error sería creer que se puede escapar de la europeidad en la medida en que no hay cultura auténtica sin arrancarse a su particularismo y abrirse a lo universal.

¿Por qué la sublimación? Sigmund Freud (1920), en su ensayo "Más allá del principio del placer", explica que el individuo, está sometido a sus instintos, bajo la formulación de sus pulsiones: la economía pulsional. La psicopatología de la vida cotidiana del ser humano está sometida a los regímenes dominados por pulsiones, donde su voluntad, su conciencia y su razón, librados a las pulsiones, solo pueden deformar bajo una forma de psicopatología.

Según Freud, la sublimación se produce en el proceso de cura cuando el sujeto adquiere los medios de deshacerse de sus estructuras neuróticas, es decir, de permanencias y repeticiones de su economía pulsional, que gobierna el principio de placer: la sublimación cultural sería la capacidad consciente e inconsciente de superar(rematar) nuestras patologías culturales, para hacernos sujetos culturales: para que una cultura se convierta en sujeto (en el sentido freudiano), para que una cultura se haga cultura (en el sentido que repetimos).

¿Cómo superar su economía pulsional, cómo conseguir el estado, siempre parcial, provisional y revisable, de sublimación cultural? Parece que la respuesta comienza con una negativa: ¡No negar la economía de sus pulsiones culturales! En una perspectiva de teoría de la cultura, no negar su economía pulsional significaría aceptar que pertenecemos todos a una cultura nativa cuya materia, forma y fin, sin hablar de su potencia actualizada, no son resultados de una elaboración de la conciencia y del trabajo de sí mismo. 
Todo ser humano, entonces, debe erigirse en contra, examinar (en el sentido de un examen de conciencia) y reflexionar (en el sentido de una elaboración racional) y alcanzar para sí mismo el objetivo de una existencia para lo universal, porque cada uno sabe que su propia cultura siempre es vista como el último criterio que domina toda visión del mundo. Las pulsiones infantiles estructuran la vida humana si esta no está sometida al proceso de la sublimación.

La sublimación es el proceso psíquico descrito por Freud como una reformación de las pulsiones en actos de ser que permiten un devenirhombre como sujeto, o sea, despejado, desplazado de sus neurosis y del imperio del principio del placer.

La sublimación cultural es el proceso que siempre queda por recomenzar. A partir de este, el sujeto adquiere un dominio potencial de sus instintos para elevarlos a la cultura. Esperamos haber propuesto la educación, la cultura con argumentos y razonamientos claros y una discusión crítica: la cultura constituye la piedra angular de la sublimación; la sublimación cultural es la condición de posibilidad de la cultura. Debo salir de las faldas de mamá; de mi cuarto de niño, de mi "zona sagrada" (Fuentes, 1991); debo extraerme de mi yo fantaseado, todopoderoso y por encima de los demás, por encima de las leyes, del mundo mismo, debo superar y sublimar mi economía pulsional para superar el hecho de estar bajo su imperio y comenzar a vivir bajo el imperio de la conciencia de sí "libre de las tutelas" culturales (y psíquicas) para obtener la facultad de vivir para lo universal.

¿Existe una hegemonía cultural que domina y estructura la educación occidental? ¿Existe un carácter eurocéntrico de la cultura que la predetermina y disminuye o elimina su aspecto universal?

Todo depende de lo que se entienda o quede sobrentendido en estas palabras. Proponemos que decir "acceder a la cultura", como expresión sujeta a la destrucción antiescolástica, significa en sí misma la esencia de la cultura europea: la cultura no es innata; es lo que educa, es aquello de lo que nos educamos; la cultura queda siempre por hacer 
y rehacer. Es esta tensión, esta tarea infinita de volverse mientras sea posible hacia lo universal.

En este sentido, una crítica bien temperada del eurocentrismo tendría que ayudar al avance de esta actitud y la búsqueda razonable de la vida para lo universal, de la misma manera como el legado de varios siglos del punto de vista sociológico e histórico facilita el desmantelamiento de muchas ilusiones que impiden o limitan nuestra capacidad de conciencia y de libertad, de apertura y de aprendizaje de lo universal. Mientras aún sepamos por qué aprender, por qué cultivarse, por qué la educación, por qué la cultura y tengamos el deseo de sobrepasar nuestras murallas y de romper nuestras cadenas psíquicas y culturales, esas que dependen ante todo de nosotros mismos, existirán candidatos a convertirse en funcionarios de lo universal, para emprender el difícil, pero sublime, camino de la vía romana. En este sentido, solo es cultura lo que toma esta vía y, aunque su método haya sido inventado en Europa, es universal, no pertenece a nadie y está disponible para todos.

\section{Epílogo. La vía romana: un humanismo de la incertidumbre}

El porvenir de la cultura, como el porvenir de Europa, es innegablemente incierto y problemático.. Acabemos de plantear preguntas imposibles, con fórmulas célebres de nuestro doctor vienés: Parece necesario indicar la finitud de la civilización, su fragilidad y su lucha por la vida, cuyo más terrible enemigo, tanto o más que la barbarie de los otros, es su propia barbarie, que amenaza con reaparecer en cualquier momento. Hemos visto que Freud lo había presentido, al igual que Valéry. Permítannos citar de nuevo el pensamiento de Freud respecto al carácter mortal de la civilización, cuyo golpe fatal puede venir de ella misma, escrita en Malestar en la cultura:

Esta "renuncia cultural" [En el texto, "Kulturversagung", es decir más exactamente la negativa de la civilización (a dejar al individuo satisfacer dichos instintos). (N.d.T.)] rige el amplio dominio de las relaciones sociales entre los humanos; y ya sabemos que en esa negativa reside la causa de la hostilidad contra la cual todas las civilizaciones tienen que luchar (Freud, 1989, pp. 27-28). 
Tratamos de apropiarnos del psicoanálisis de los instintos que luchan entre ellos y con lo real, vemos de qué manera sería fructífero de adoptarlo y transformar su concepto de sublimación, con el fin de proponer una reformulación de la idea de cultura introducida por Brague: la vía romana. "La idea de cultura, de inteligencia, de obras magistrales está, para nosotros, en una relación muy antigua — tan antigua como volvemos raramente hasta ella — con la idea de Europa" (Valéry, 1957, p. 995).

Dice Valéry, si "no todo se ha perdido", “todo se sintió perecer". Por cierto, en su admirable exposición, en un acento nietzscheano, creación y destrucción están estrechamente vinculadas, ya que ha llegado el tiempo en que "los poderosos medios de producción se transforman en pocos días en poderosos medios de destrucción", [puesto que] "nosotros, las civilizaciones, sabemos ahora que somos mortales". De este modo, se nos ofrece la oportunidad de tomar una nueva conciencia de sí mismo. Por el hecho de que somos conscientes de nuestra fragilidad —que, según Brague, es solo una manera de expresar-, nos hallamos en situación de recordar y revivificar la "idea de Europa", para mirar y actuar de otro modo sobre el futuro. Esta "idea de Europa" no es la lettre de cachet de "limpieza de sangre", sino la idea misma de la cultura, a la cual el ser humano debe defender porque al preservar esta manera singular de hacer cultura, se preserva a sí mismo, en la medida en que no es ángel ni bestia (la desgracia consiste en que precisamente el hombre sueñe constantemente en verse en ángel, cual gesto que menudas veces lo puede hacer convertir en bestia, como Blaise Pascal (2004) lo comentaba con su clásica agudeza). Su tarea humana es de llegar a ser humano capaz de esa aptitud para tender e introducir en sí mismo, en su propia vida, el sentido de lo universal. Permítannos acabar este ensayo con esta cita de Fuentes (1993): "Leer una novela es un acto amatorio que nos enseña a mejor amar".

Si se transformase la palabra lectura en cultura, la palabra novela en individuo, la palabra enamorado / amor en vivir, podría hacerse una hermosa reformulación, ciertamente poética, de lo que hemos tratado de decir sobre la sublimación cultural o podría ser que esas palabras de Fuentes convengan perfectamente a nuestra intención. 


\section{Referencias bibliográficas}

Agamben, G. (1997). Homo sacer. I, Le pouvoir souverain et la vie nue. (M. Raiola, trad.). París: Seuil. (Original publicado en 1995).

Assoun, P. L. (1998). Freud et Nietzsche. París: PUF.

Bourdieu, P. (1982). Choses dites. París: Seuil.

Bourdieu, P. (2003). Méditations pascaliennes. 2a ed. París: Seuil.

Bouveresse, J. (1984). Rationalité et cynisme. París: Éditions de Minuit.

Brague, R. (1998). Athens, Jerusalem, Mecca. Leo Strauss' "Muslim” Understanding of Greek Philosophy. Poetics Today, Hellenism and Hebraism Reconsidered: The Poetics of Cultural Influence and Exchange, II (19), 235-259. Brague, R. (2005). La loi de Dieu. Histoire philosophique d'une alliance. París: Folio-Gallimard.

Brague, R. (2008). Au moyen du Moyen Âge. París: Champs-Flammarion.

Brague, R. (2009a). Europe, la voie romaine. París: Folio.

Brague, R. (2009b). Eccentric Culture: A Theory of Western Civilization. South Bend: Saint Augustine's Press.

Castoriadis, C. (1996). La Montée de l'insignifiance (Les carrefours du labyrinthe IV) - París: SeuilColliot-Thélène, C. (2001). Études wébériennes. Rationalités, histoires, droits. París: Presses Universitaires de France.

Colliot-Thélène, C. (1989). Rationalisation et désenchantement du monde: problèmes d'interprétation de la sociologie des religions de Max Weber. Archives des sciences sociales des religions, 89 (89), 61-81.

Colliot-Thélène, C. (1990). Max Weber et l'histoire. París: PUF.

Conrad, J. (2007). Nostromo. Londres: Penguin Classics.

De Sousa Santos, B. (2009). Epistemología del sur. México: siglo XXI Editores.

Deleuze, G., y Guattari, F. (1991). Qu'est-ce que la philosophie? París: Éditions de Minuit.

Dube, S. (1999). (Ed.) Pasados poscoloniales: Colección de ensayos sobre la nueva historia y etnografía de la India, trad. G. Franco, Ciudad de México, El Colegio de México.

Dussel, E. (1992). 1492: El encubrimiento del otro. Hacia el origen del "mito de la modernidad". Conferencias de Frankfurt. La Paz: Plural Editores.

Elias, N. (2012). On the Process of Civilization. Dublin: University College Dublin Press. 
Freud, S. (1965). Cinq leçons de psychanalyse. París: Petite Bibliothèque Payot. Freud, S. (1989). Malaise dans la civilisation. (11 ed.) París: PUF.

Freud, S. (1973). Essais de psychanalyse. París: Petite Bibliothèque Payot.

Freud, S. (2010a). Au-delà du principe de plaisir. París: PUF.

Freud, S. (2010b). Psychologie des masses et analyse du moi. París: PUF.

Fuentes, C. (1991). Dos educaciones. Las buenas conciencias. Zona sagrada. Barcelona: Mondadori.

Fuentes, C. (1993). Geografía de la novela. Barcelona: Joaquín Mortiz.

Gemes, K. (2009). Freud and Nietzsche on Sublimation. Journal of Nietzsche Studies, (38), 38-59.

Kant, E. (2006). Vers la paix perpétuelle. Et autres textes. París: GF-Flammarion. Kolakowski, L. (1986). Le village introuvable. Bruselas: Complexe.

Lévinas, E. (1997). Difficile liberté. Essais sur le judaïsme (1963, 1976). París: Biblio-essais.

Manent, P. (1994). La cité de l'homme. París: Flammarion.

Manent, P. (2010). Les métamorphoses de la cité. Essai sur la dynamique de l'Occident. París: Flammarion.

Manon, S. (2008). Plaidoyer pour l'Europe ou l'Occident. L'exception européenne. Recuperado de www.philolog.fr

Marco Aurelio. (1992). Pensées pour moi-même. París: M. Meunier, GF.

Miller, P. (1998). Malaise dans le psychanalyste. Revue française de psychanalyse, La Sublimation T. LXII, 1041-1062.

Nietzsche, F. (1906). Humain, trop humain. (A. M. Desrousseaux, trad.). París: Mercure de France. (Original publicado en 1886).

Pinto, L. (1995). Les neveux de Zarathoustra: la réception de Nietzsche en France. París: Seuil.

Renan, E. (1882). Qu'est-ce qu'une nation ? : Conférence faite en Sorbonne, le 11 mars 1882, París: Calmann Lévy.

Ricœur, P. (1990). Soi-même comme un autre. París: Éditions du Seuil.

Said, E. (1978). Orientalism. Nueva York: Knopf Doubleday.

Sperber, D. (1985). On Anthropological Knowledge. Cambridge: Cambridge University Press.

Sperber, D. (1998). Explaining Culture: A Naturalistic Approach. Oxford: Blackwell.

Sperber, D. (2011). A Naturalistic Ontology for Mechanistic Explanations in the Social Sciences. En P. Demeulenaere (ed.), Analytical Sociology and SocialMechanisms (pp. 64-77). Cambridge: Cambridge University Press. 
Stroumsa, G. (2010). A New Science: The Discovery of Religion in the Age of Reason. Cambridge: Harvard University Press.

Taubes, J. (2009). Eschatologie occidentale. París: Editions de l'Eclat.

Valéry, P. (1957). La crise de l'esprit, Variété I. En J. Hytier (ed.), CEuvres (pp. 988-1015). París: Gallimard.

Voegelin, E. (1952). The New Science of Politics. An Introduction. Chicago: University of Chicago Press.

Voegelin, E. (2003). The Collected Works of Eric Voegelin, Volume 31: Hitter and the Germans. D. Clemens y B. Purcell (eds.). Londres: University of Missouri Press. 